\title{
Research on heat storage materials in solar thermal power system
}

\author{
Zhang Xudong \\ North China Electric Power University, 102206 Beijing, China
}

Received December 26, 2018

\begin{abstract}
In this paper, through the collation and analysis of the literature related to phase change heat storage materials, the screening principle of the heat storage materials is proposed. Then the current hot spot molten salt and metal alloy phase change heat storage materials performance and research and development status are systematically summarized and analyzed. Finally, an economic analysis of thermal performance was performed. This paper has important reference value for the development and research of high temperature phase change heat storage technology for solar thermal power generation.

Keywords: heat storage material, high temperature molten salt, economy.

В статье путем сопоставления и анализа литературы, относящейся к теплоаккумулирующим материалам с фазовым переходом, предлагается принцип выбора и создания материалов для экранирования и аккумулирования тепла. Систематически обобщаются и анализируются характеристики теплоаккумулирующих материалов расплавленной соли и металлических сплавов. Проведен экономический анализ их характеристик. Статья имеет важное справочное значение для разработки и исследования высокотемпературной технологии накопления тепла с фазовым переходом для аккумулирования солнечной тепловой энергии.
\end{abstract}

Дослідження теплоакумулюючих матеріалів з фазовим переходом для сонячного теплопостачання. Zhang Xudong.

У статті шляхом зіставлення та аналізу літератури, що відноситься до теплоакумулюючих матеріалів з фазовим переходом, пропонується принцип вибору і створення матеріалів для екранування i акумулювання тепла. Систематично узагальнюються $\mathrm{i}$ аналізуються характеристики теплоакумулюючих матеріалів розплавленої солі і металевих сплавів. Проведено економічний аналіз їх характеристик. Стаття має важливе довідкове значення для розробки і дослідження високотемпературної технології накопичення тепла з фазовим переходом для акумулювання сонячної теплової енергії.

\section{Introduction}

The utilization of solar thermal power generation is an important means to effectively alleviate the energy shortage, resource depletion and environmental problems brought about by thermal power generation in the future. The concentrated solar power (CSP) technology is relatively mature, the power generation cost is low, and has a good match with the grid. Moreover, its thermoelectric conversion part is the same as the conventional thermal power generator sets, which has relatively mature technology and is suitable for large-scale concentration. So, thermal power generation is one of the most promising forms of renewable energy generation. However, the solar radiation intensity has the characteristics of volatility, etc. The power load also has a peak-to-valley gap, resulting in a time and space mismatch between energy supply and demand, and the power generation system is difficult to operate smoothly. Therefore, a heat storage system is used to store some of the collected solar energy.

The heat storage methods mainly include sensible heat storage, latent heat storage 
(phase change heat storage) and chemical reaction heat storage. Among them, phase change heat storage has advantages that are difficult to compare with other two methods. For example, the latent heat of phase change is large, the heat storage density is high, the heat absorption process is approximately constant temperature, and the process is easy to control. It is the most promising heat storage method at present. The performance of phase change heat storage materials directly affects the performance and cost of the entire heat storage system. The available data show that a large number of materials can undergo phase change at a certain temperature while releasing or absorbing latent heat. However, it should be used as a heat storage medium, and at the same time, comprehensively measure its thermal properties, corrosively, economy and other factors. Faced with a variety of phase change heat storage materials (more than 160000 ) and various factors that need to be considered simultaneously, it is a complicated and time-consuming task to screen out the best phase change materials that meet the requirements, but it is also solar thermal utilization. The key issues that need to be addressed urgently.

In this paper, through the collation and analysis of related literatures, the screening principles of phase change thermal storage materials are summarized, and the research and development status and future development trends of high temperature molten salt materials and phase change metal alloy materials with the most development potential are summarized and analyzed. The key issues that should be addressed in the future development of phase change heat storage technology will provide reference for the development of high temperature phase change heat storage technology in the future.

\section{Screening principles for phase change heat storage materials}

The phase change materials used to store latent heat depend on many factors such as material properties, storage capacity, operating temperature, heat transfer fluid properties, and heat exchanger design. The performance of all aspects of the selected materials will directly affect the heat storage system and the heat storage/heat efficiency. Therefore, the screening mainly meets the following principles:

1. Meet the thermal performance requirements.
Suitable phase transition temperature. This allows the material's ideal operating temperature to be optimally matched to its application temperature, allowing it to operate optimally.

Larger phase changes latent heat and higher specific heat capacity. The latent heat of phase change means that more latent heat can be stored at the same phase transition temperature, and the higher specific heat capacity determines that more sensible heat can be stored under the same temperature difference. Therefore, the material that satisfies this requirement has a large total heat storage capacity and a high heat storage density.

Large thermal conductivity. The material with high thermal conductivity has good thermal conductivity, and the temperature gradient required for the absorption and release process of the same heat is small, and the heat storage, heat extraction speed and high efficiency are high.

Consistent melting. The chemical composition of different phase states before and after the material phase change is consistent, and the phase separation phenomenon caused by the difference of solid-liquid twophase density can be avoided.

2. Meet physical performance requirements

Good phase balance. The phase change process of the material is required to be completely reversible and only temperature dependent.

The vapor pressure is low. The corresponding steam pressure at the working temperature is low and the material is not volatile.

Density is large. For different materials with phase change latent heat and specific heat capacity, the large heat storage per unit volume is large, which helps to reduce the cost of the container.

Smaller volume. The small volume expansion ratio means that the type of the system heat storage heat exchanger is allowed to be simplified while ensuring a certain heat transfer rate. For example, assuming a $10 \%$ reduction in volume when the medium solidifies, then for a horizontally placed round tube, the effective heat transfer area will be reduced by $25 \%$ when the gap is at the top. Due to factors such as solidification speed, viscosity and surface tension of the medium, the voids may also be dispersed throughout the heat storage medium, which results in a decrease in the thermal conductivity of the heat storage medium and a decrease in heat transfer rate. 
3. Meet the requirements of dynamic performance.

The degree of subcooling during solidification is as small as possible, and there is no supersaturation when melting.

Crystallizes fast.

4. Meet the chemical performance requirements.

Chemical stability is good. After repeated absorption and release of heat, the material does not undergo melting and side reactions, and is not easy to be chemically decomposed. Therefore, the heat storage capacity is weakened after long-term service, and the application is feasible and reliable, which can ensure the system has a certain service life.

Less corrosive, anti-oxidation. The high corrosivity of the material at high temperatures means compatibility with a variety of materials, and the wide selection of container materials can reduce the cost of the container.

In line with green chemical requirements: non-toxic, non-polluting, non-flammable, not explosive, safe to use.

5. Meet economic performance requirements.

Raw materials are easy to obtain, and the cost is low.

It has industrial utility.

6. Meet technical performance requirements.

The materials selected should be technically as efficient, compact, reliable and suitable as possible. In the actual development process, it is difficult to find that it can be satisfied at the same time. Ideal materials for the above requirements, therefore, priority should be given to the appropriate phase transition temperature, high latent heat of phase change and low price, and then consider various comprehensive factors. In addition, some technical means can be taken to compensate for the unsatisfactory performance. If the nucleating agent and the thickener can be added to improve the supercooling of the crystal water and the salt, for the case of poor heat transfer, some means for enhancing the heat transfer can be adopted.

\section{High temperature phase-change heat storage material}

\subsection{High temperature molten salt}

High-temperature molten salt generally refers to nitrates, chlorides, carbonates and their co-crystals. It has the advantages of "four highs and three lows", namely high use temperature, high thermal stability, high specific heat capacity, high convective heat transfer coefficient and low viscosity. The saturated vapor pressure is low and the price is low. At the same time, it has a certain latent heat of phase change, so its heat transfers and heat storage properties are excellent, and it is very suitable for use as a heat storage material for solar thermal power generation systems. In terms of cost, general lithium salt $>$ potassium salt $>$ sodium salt $>$ calcium salt.

In practical applications, a single salt is rarely used, and most of the binary and ternary inorganic salts are mixed and eutectic to form a mixed molten salt. The main advantage of mixed salt is that the desired melting point can be obtained by appropriately changing the proportion of its components, and the applicable temperature range is wider; it can meet the higher energy density at lower melting temperature; Highquality materials with good thermal properties are used together with low-priced materials to save costs, while heat capacity can be kept approximately unchanged. At present, most researches on high-temperature molten salt in the field of solar thermal power generation tend to use it as sensible heat storage material or as a heat exchange fluid, and only sensible heat storage forms have been applied to a certain scale. Such as Solar salt (40 \% $\mathrm{KNO}_{3}-60 \%$ NaNO), Hitec $\left(\begin{array}{lllllll}40 & \% & \mathrm{NaNO}_{2}-7 & \% & \mathrm{NaNO}_{3}-53 & \% & \mathrm{KNO}_{3}\end{array}\right)$ and Hitec XL $\left(48 \% \mathrm{Ca}\left(\mathrm{NO}_{3}\right)_{2}-45 \% \mathrm{KNO}_{3}-\right.$ $7 \% \mathrm{NaNO}_{3}$ ) Wait. Italy's Eurelios power station and Spain's CESA-1 power station use Hitec salt as a heat storage medium [6]. Solar Two in the US and Solar Tres and Andasol power stations in Spain use Solar Salt as a heat storage material [7]. In July 2008, the Italian National Power Group started construction of the world's first Archimedes solar thermal power station that uses Sol Salt as a heat storage medium and simultaneously acts as a heat transfer medium in Sicily. $5 \mathrm{MW}$, officially put into operation in July 2010 [8]. Table 1 and Table 2 show the main performance parameters and costs of these three molten salts [9].

It can be seen from the table that the heat capacity of the three is limited and the heat storage density is low. Therefore, hundreds of tons of molten salt and a large storage container are usually required in practical applications, and the freezing temperature of the three is much higher than 
Table 1. Characteristics of three commercial high-temperature molten salts

\begin{tabular}{|c|c|c|c|}
\hline Property & Solar salt & Hitec & Hitec XL \\
\hline Freezing point, ${ }^{\circ} \mathrm{C}$ & 220 & 142 & 120 \\
\hline Decomposition temperature, ${ }^{\circ} \mathrm{C}$ & 600 & 535 & 500 \\
\hline Ensity $^{*},\left(\mathrm{~kg} / \mathrm{m}^{3}\right)$ & 1899 & 1640 & 1992 \\
\hline Viscosity*$^{*} \mathrm{cp}$ & 3.26 & 3.16 & 6.37 \\
\hline Thermal capacity* $(\mathrm{J} /(\mathrm{kg} \cdot \mathrm{K}))$ & 1495 & 1560 & 1447 \\
\hline
\end{tabular}

* - measured when the corresponding data is $300^{\circ} \mathrm{C}$.

the ambient temperature, although it can be appropriately. Optimized composition and ratio have been reduced to some extent, but the freezing point protection measures are still needed when using, which increases the cost and complexity of the equipment. Only relying on sensible heat to store heat, heat storage performance and heat storage cost cannot be guaranteed at the same time, cannot meet large-scale commercial applications. It must be noted that the high-temperature molten salt has a large heat capacity and a high latent heat of phase change, and can simultaneously store sensible heat and latent heat by means of phase change heat storage, so that the heat storage capacity can be greatly improved, so. It is of great significance to develop high-temperature molten salt phase change heat storage materials with low cost and excellent performance.

\subsection{Metal alloy}

Although high-temperature molten salt has the advantages of high operating temperature, low vapor pressure and large heat capacity, it still needs to overcome problems such as low thermal conductivity and solidliquid stratification. The thermal conductivity of metal alloy materials is several tens to hundreds of times higher than other phase change heat storage materials, and it has many advantages such as high heat storage density and good thermal cycle stability, and has great development potential. The use of molten metal alloys as heat transfer fluids in nuclear power plants is mainly due to the use of metal alloys. Among the alloy materials, the phase transition temperature of aluminum-based alloys is suitable, and it has relatively low corrosivity. It has become the focus of research on metal alloy phase change heat storage materials, and has a good application prospect in high-temperature heat storage of solar thermal power generation.

As early as in the 1980s, American scholar Birchenall, French scientist Achard,
Table 2. Electricity cost of three commercial high-temperature molten salts

\begin{tabular}{||c|c|c|c||}
\hline Name & $\begin{array}{c}\text { Temperature } \\
\text { rise, }{ }^{\circ} \mathrm{C}\end{array}$ & $\begin{array}{c}\text { Price, } \\
(\$ / \mathrm{kg})\end{array}$ & $\begin{array}{c}\text { Thermal } \\
\text { storage } \\
\text { costs, } \\
(\$ /(\mathrm{kW} \cdot \mathrm{h}))\end{array}$ \\
\hline $\begin{array}{c}\text { Solar salt } \\
\left(220^{\circ} \mathrm{C}\right)\end{array}$ & 200 & 0.49 & 5.8 \\
\hline $\begin{array}{c}\text { Hitec } \\
\left(142^{\circ} \mathrm{C}\right)\end{array}$ & 200 & 0.93 & 10.7 \\
\cline { 2 - 4 } & 200 & 1.19 & 15.2 \\
\hline \multirow{2}{*}{$\begin{array}{c}\text { HitecXL } \\
\left(120^{\circ} \mathrm{C}\right)\end{array}$} & 150 & 1.19 & 20.1 \\
\cline { 2 - 5 } & 100 & 1.19 & 30 \\
\hline
\end{tabular}

and Russian scientist Cherneeva et al. [10] conducted experimental studies on aluminum-based binary and multi-component alloys. The results showed that various aluminums were studied. The base alloy not only has suitable phase transition temperature $\left(327^{\wedge} \sim \wedge 657^{\circ} \mathrm{C}\right)$, high latent heat of phase change, but also high thermal conductivity and good thermal stability. Compared with high temperature molten salt, its heat storage performance is obviously improved, but the most obvious defect It is highly corrosive in liquids, which means that higher requirements are imposed on the corresponding container materials. Gasanaliev et al. [11] tested the phase transition temperature and latent heat of phase change of various aluminum-based binary and multicomponent alloys including $\mathrm{Si}, \mathrm{Cu}$, and $\mathrm{Mg}$. Kenisarin [10] and Liu et al. [12] summarized the thermophysical and corrosive properties of a large number of metal alloy phase change heat storage materials.

In China, Zou Xiang et al. [13] of the Guangzhou Institute of Energy, Chinese Academy of Sciences conducted an early study on the heat storage performance and cycle stability of Al-Si alloys. The results show that Al-13Si (mass percent, the same below) alloy after 720 thermal cycles. The latent heat of phase change decreased by $10.5 \%$, and the phase transition tempera- 
ture remained basically unchanged. Huang Zhiguang, a professor at Huazhong University of Science and Technology [14], has shown that Al-Si-Mg alloys have the best heat storage capacity, and Al-Si-Cu alloys have the longest life. It is an Al-Si alloy. In addition, different methods have been used to conduct calorimetric analysis of $\mathrm{Al}-\mathrm{Si}$ alloys with different Si contents. The results show that the latent heat and specific heat of the alloy phase change are different when the Si content, the number of cycles and the holding time are different. Variety. Zhang Renyuan et al. [8] of Guangzhou University of Technology discussed in detail the causes of metal liquid corrosion at high temperatures, and pointed out that time temperature, and melt composition are the main factors affecting corrosion. Liu Jing et al. [15] measured and analyzed the properties of $\mathrm{Al}-12 \mathrm{Si}$ alloy, and considered that $42 \mathrm{Sr}-\mathrm{Mo}$ heat resistant steel is more suitable for its container material. Cheng Xiaomin et al. [16] successfully prepared 20 kinds of aluminum-based multi-alloys suitable for solar energy high-temperature phase change heat storage, analyzed the influence of different elements on the melting point and latent heat of phase change of the alloy, and summarized some scholars on iron. Research on the corrosion mechanism of the base alloy aluminum liquid has proposed several feasible anti-aluminum liquid corrosion measures. Sun Jianqiang et al. [17] measured the thermal properties of Al$34 \mathrm{Mg}-6 \mathrm{Zn}$ and studied the compatibility between the alloy and stainless steel and carbon steel. The results show that the melting temperature does not increase with the increase of thermal cycle. Change, but the heat of fusion is slightly reduced. Zhang Guocai et al. [18] showed that the latent heat of phase change of Al-13Si (mass percent, the same below) alloy decreased by $10.5 \%$ after 720 thermal cycles, and the phase transition temperature remained basically unchanged.

There are many studies on the thermal properties of metal alloy phase change materials, but considering the application in the field of heat storage, these studies are still insufficient. The temperature and phase of the heat storage material change with the process of charging and releasing heat of the system, and the corresponding thermal property parameters often change more or less, which is related to the heat storage and heat transfer performance of the system, which affects the efficiency and cost. However, at present, the research on the change law of thermal properties of alloy materials is obviously insufficient, especially the thermal conductivity coefficient. The thermal conductivity values of many new alloy materials with large heat storage are not even available. The thermal properties of metal alloy phase change heat storage materials can be seen. It is still necessary to carry out systematic data accumulation and regular analysis. The metal alloy has a strong heat storage capacity and a large thermal conductivity, which is undoubtedly the advantage. However, the liquid corrosion is high under high temperature conditions, resulting in poor compatibility with the container material, which is to limit the metal alloy in the field of high temperature phase change heat storage. The biggest reason for the actual application. Although there have been a lot of studies on the compatibility of alloys and container materials at home and abroad, most of them are relatively scattered, lacking systematicity and regularity. Therefore, the problem of material compatibility should be further studied, and a reasonable packaging method should be sought to finally realize the wide application of metal alloys in the field of high temperature phase change heat storage.

\section{Economic analysis of PCMs in solar power system}

\subsection{Mathematical model}

The solar thermal power generation system is mainly composed of a heat source, a phase change heat storage system, a heat network, and heat users. When combined with coal-fired units, solar energy provides a heat source for the system, and the phasechange energy storage system recycles heat. The insufficient part is provided by a coalfired boiler. This process has both energy flow and material flow.

The operating principle of the system is to integrate the medium and low temperature solar thermal energy into the power plant regenerative system by using the collector, and at the same time, use the collector to heat the feed water of the regenerative system heater. Excess heat energy can be stored by phase change energy storage materials, reducing coal consumption and increasing active power, while solar power generation costs are greatly reduced.

In the solar composite thermal power generation system, the unit price of solar energy is only 0 yuan, and only the unit 
price of coal burning needs to be considered. The solar-assisted coal-fired thermal power generation system is regarded as two independent circulation systems, one is the coal-fired circulation system of the boiler, and the other is the solar heat collection and circulation system. The unit energy cost of each unit is:

$$
K_{\pi}=K_{p s i C s}+K_{p b i C b}=K_{p b i C b},
$$

where $K_{p s i C s}-$ solar energy consumption per unit of product $i$; $C_{s}-$ solar unit heat price, value of zero; $C_{b}-$ fuel coal unit heat price.

When any of the $j$-th heaters in the regenerative system introduces external heat $q_{j}$, the heat transfer efficiency of heat $q_{j}$ can be expressed by the pumping efficiency $\eta_{j}$ of the pumping stage:

$$
\eta_{j}=\frac{W_{j}}{q_{j}},
$$

where $W_{j}$ - the gained work of $j$-th heater by reducing $1 \mathrm{~kg}$ pumping; $q_{j}$ - the external heat of the $j$-th heater by reducing $1 \mathrm{~kg}$ pumping.

When the external heat in Equation 2 comes from a solar collector, the required solar energy of the $j$-th to reduce $1 \mathrm{~kg}$ pumping is:

$$
q_{s j}=\frac{q_{j}}{\eta_{c} \cdot \eta_{d}},
$$

where $\eta_{c}$ - the efficiency of solar collector; $\eta_{d}$ - the efficiency of channel.

The total heating efficiency of solar energy collector is:

$$
\eta_{s j}=\eta_{j} \cdot \eta_{c} \cdot \eta_{d}
$$

where the solar collector efficiency is:

$$
\begin{gathered}
\eta_{c}=\frac{Q_{u}}{(3600 \cdot A \cdot I)} \\
Q_{u}=D \cdot\left(i^{\prime \prime}-i^{\prime}\right),
\end{gathered}
$$

where $Q_{u}$ - the output heat of solar collector; $A$ - the area of solar collector $\left(\mathrm{m}^{2}\right) ; I-$ the intensity of solar radiation $\left(\mathrm{KW} / \mathrm{m}^{2}\right) ; D$ - the water flow rate of solar collector $(\mathrm{kg} / \mathrm{h}) ; i^{\prime \prime}, i^{\prime}-$ the enthalpy of condensate at entrance and exit of solar collector.

Due to the rise of the wall temperature of the heat collecting tube, the heat loss of the radiation and convection is increased.

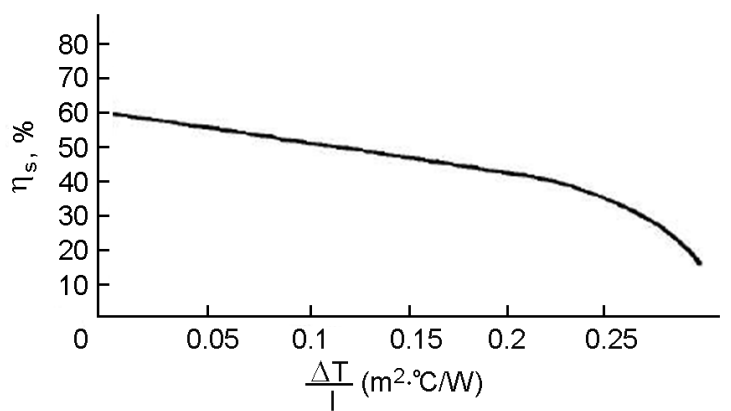

Fig. The plot of the thermal efficiency and the solar radiation intensity.

Therefore, the efficiency of the solar collector decreases as the temperature of the condensed water in the heat collecting tube increases. If the received solar energy is the same, the useful heat for heating condensate is reduced, making the condensate enthalpy in Equation 6 smaller.

\subsection{Model analysis results}

In this paper, a $330 \mathrm{MW}$ thermal power unit is selected as a calculation example of a composite power generation system, and an array of CPC vacuum tube solar collectors is used. The no phase change material heat storage system is set as the first scheme, and the phase change material heat storage system is set as the second scheme. Thermal efficiency analysis is conducted. Figure is a plot of the thermal efficiency of the collector versus the solar radiation intensity. The results are all calculated according to this radiation intensity. It can be seen that under the premise of sufficient solar energy, with the change of time, that is, the irradiance increases, the solar water heater absorbs heat, so the inlet steam parameter is kept consistent with the target parameter by increasing its influent flow rate.

Set the solar operating hours as $3285 \mathrm{~h}$, and the irradiance as $860 \mathrm{Wm}^{2}$. In the first scheme, the solar collector system provides $69.28 t / h$ of main steam, and in the second scheme, the solar collector system provides $83.68 t / h$ reheat cooling section steam, that is replacing part of the two-stage extracted steam. In the third scheme, the solar collector system provides $65.199 t / h$ of reheating heating section steam, comprehensively considering the various levels of steam extraction and steam supply changes from tower solar collector systems to steam turbines caused by changes in water supply, thus obtaining steam turbine work, thermal power conversion efficiency and solar thermal power generation efficiency. The inlet 
water temperature of the solar collector is $280.16^{\circ} \mathrm{C}$, the inlet water pressure is 19.5 Mpa, the inlet water ratio is $1232.2 \mathrm{~kJ} / \mathrm{kg}$, the outlet water temperature of scheme 1 is $551^{\circ} \mathrm{C}$, and the outlet water temperature of scheme 2 is $335.5^{\circ} \mathrm{C}$. The outlet water temperature of Scheme 3 is $548^{\circ} \mathrm{C}$, and the same quality steam parameters are shown in Table 3. Through comparative analysis, it is concluded that the first option is a better choice. The net solar power generation efficiency is $41.9 \%$, but the thermal power conversion efficiency of the composite power generation system is decreased by $1.8 \%$ compared with the coalfired unit THA, which is because the cyclic heat absorption contains heat from the solar collector system.

\section{Conclusions}

The development and selection of heat storage materials is the key to the development of solar thermal power storage technology, but the current research is still not perfect. Based on the investigation of the research and development status of solar thermal power generation high temperature phase change heat storage materials, this paper will related research work has been prospected and the main conclusions are as follows:

- The principle of material selection is to meet the requirements of many aspects such as thermodynamics, kinetics, chemistry and economy. For the actual application, when selecting materials, we can not only measure the advantages and disadvantages of the materials themselves, but also consider a variety of objective factors (such as heat transfer conditions). The actual materials should meet various conditions at the same time. After ensuring that the main conditions (phase transition temperature and latent heat of phase change) are met, some technical means are developed to make up for their shortcomings and shortcomings.

- The study of molten salt for phase change heat storage in the high temperature field is not sufficient. The thermal conductivity of high-temperature molten salt is generally low, which affects the heat storage and heat release characteristics of the system. Therefore, the study of thermal properties of high-temperature molten salt materials (especially the thermal conductivity in solid state) is a further promotion of high-temperature molten salt phase change heat storage materials. The key to widespread application.
Table 3. Solar thermal efficiency

\begin{tabular}{||c|c|c||}
\hline Project & Program 1 & Program 2 \\
\hline Solar heat, kg/h & 69300 & 83682.23 \\
\hline Output power of solar, kw & 27473.89 & 20897.41 \\
\hline $\begin{array}{c}\text { Net solar power } \\
\text { generation rate, \% }\end{array}$ & 41.9 & 33 \\
\hline Thermal efficiency, \% & 42.8 & 42.6 \\
\hline $\begin{array}{c}\text { Standard coal } \\
\text { consumption rate, g/KW·h }\end{array}$ & 322.3 & 323 \\
\hline
\end{tabular}

- The heat storage performance of metal alloys, especially aluminum-based alloys, is significantly better than that of high-temperature molten salts. If the problem of strong liquid corrosion under high temperature conditions is solved, it will surely usher in the wide application of metal alloy phase change heat storage. Therefore, the compatibility and alloy of metal alloys with container materials. The effective packaging of materials is an important directing for further research.

- Although many scholars at home and abroad have developed and studied a variety of high temperature phase change heat storage materials, the accumulation of relevant data is far from enough, especially the metal alloy phase change heat storage materials and the different ratio parameters and enhanced heat transfer means The phase change heat law and the change law of thermal properties of molten salt greatly affect the development of phase change energy storage technology.

In the related research published, most of the information on high temperature phase change heat storage materials lacks integrity. While actively experimenting and developing new materials, it is necessary to pay attention to the improvement of all aspects of materials, such as thermal conductivity in the working temperature range, thermal properties such as specific heat capacity in different phase states, and other factors such as cost and environmental impact. A more comprehensive measure of its application value.

\section{References}

1. D.Zhang, C.Y.Zhao, T.Tina, Int.J.Appl.Energy, 92, 593 (2012).

2. M.Barbagallo, S.Finnveden, Int. J.Engin. Sci., 63, 71 (2013).

3. B.Zalba, J.M.Marin, L.F.Cabeza, Int.J.Appl. Energy, 23, 251 (2003).

4. Yuan Jianli, Han Wei, Jin Hongguang et al., Int. J. Proc. CSEE, 30, 115 (2010). 
5. Li Xin, Li Anding, Li Bin et al., Int.J.Proc. CSEE, 25, 108 (2005).

6. Yin Huibin, Ding Jing, Yang Xiaoxi, J.Engin. Therm. Energy and Power, 1, 105 (2013).

7. R.I.Dunn, P.J.Hearps, M.N.Wright, Proc. $I E E E, 100,504$ (2012).

8. CSP. Brief Introduction of Archimedes 5MW Solar Thermal Power Plant Project in Italy[EB/OL].Beijing China:CSPPLAZA, 2012(07-31)[2013-05-28].http://www.cspplaz a.com/article-517-1. Html

9. D.Kearney, U.Herrmann Nava, J.Solar Energy Engin., 125, 170 (2003)
10. C.E.Birchenall, A.F.Riechman, Metall.Mater. Trans. A, 11, 1415 (1980).

11. A.M.Gasanaliev, B.Y.Gamataeva, Russian Chem. Rev., 69, 179 (2000).

12. M.Liu, W.Saman, F.Bruno, Renewable Sustainable Energy Rev., 16, 2118 (2012).

13. Cheng Xiaomin, He Gao, Wu Xingwen, Mater. Rev., 17, 139 (2010).

14. Huang Zhiguang, Xiao Sinong Wu, J.Engin. Thermophys., 12, 46 (1991).

15. X.Wang J.Liu, Y.Zhang et al., Energy Conversion Management, 47, 2211 (2006).

16. Cheng Xiaomin, Dong Jing, Wu Xingwen et al., Heat Treatment Metals, 35, 13 (2010). 